\title{
The non-selective use of profundaplasty in lower limb ischaemia
}

\author{
Brian P. HeATHER \\ F.R.C.S.
}

\author{
Colin C. WARE \\ F.R.C.S.
}

Southend-on-Sea Hospital, Essex

\begin{abstract}
Summary
Previous publications on profundaplasty are reviewed. Results are presented of the use of profundaplasty alone as the sole treatment in 99 limbs with femoropopliteal occlusion. An improvement rate of $77 \%$ is recorded in claudicants together with a $28 \%$ limb salvage rate in gangrenous limbs. The present place of profundaplasty in treatment of femoro-popliteal occlusion is discussed.
\end{abstract}

\section{Introduction}

The ability of the profunda femoris artery and its branches to maintain a viable and, in certain circumstances, normally functioning lower limb in the presence of an occluded superficial femoral artery has long been recognized.

Leeds and Gilfillan (1961) and Morris et al. (1961) both described the successful treatment of groups of patients with combined aorto-iliac and femoropopliteal disease by aorta to common femoral artery bypass grafting together with an endarterectomy of the common femoral artery and profunda femoris origin where indicated.

Farley, Kiser and Hitchcock (1964) described an unusual operation in which a vein graft was interposed between the termination of the main profunda femoris artery and the popliteal artery via a posterior approach, enabling an infected femoro-popliteal graft to be removed without sacrificing the limb, but operations restricted to the common femoral bifurcation were not widely accepted at that time. Waibel (1966), with a description of profunda femoris origin reconstruction using a flap from the occluded superficial femoral artery, is the first of a series of authors to describe procedures to increase profunda femoris blood flow without surgery to more proximal vessels.

Interest in the profunda femoris artery increased in subsequent years, attention still mainly centring on its ability to provide adequate distal run-off for proximal bypass or endarterectomy when the superficial femoral artery was occluded, although papers by Martin, Renwick and Stephenson (1968), Youmans, Hopkins and Derrick (1969), Killen (1969) and Cohn, Trueblook and Crowley (1971) include small numbers of patients in whom surgery to the common femoral artery and profunda femoris $\omega_{\sigma}$ origin, by endarterectomy or patch grafting, was: the sole procedure.

The use of profundaplasty as an operation in its own right has expanded rapidly in recent years and 0 several widely differing techniques are described. $\stackrel{A}{0}$ Berguer, Higgins and Cotton (1975) have stressed the importance of extending any reconstructive $\varnothing$ procedure distally at least as far as the first major 0 generation of branches of the diseased profunda $\rightarrow$ femoris artery and the majority of surgeons achieve $z$ this with an autogenous vein patch of $4-5 \mathrm{~cm}$ with or without endarterectomy. However, Harper and $\frac{\Phi}{3}$ Millar (1977) have reported success using a vexy short vein patch to the profunda femoris origin onls, whilst Berguer, Cotton and Sabri (1973), emphe sizing that atheroma may not be localized to te profunda origin, have described the operation of extended deep femoral angioplasty utilizing a vein patch of up to $15 \mathrm{~cm}$. Amongst other techniques recorded are long semi-closed endarterectomy of the profunda femoris artery (Kiely, Lumley and Taylor, $\stackrel{\odot}{\varnothing}$ 1973) and common femoral artery to profunda $\stackrel{2}{\vec{F}}$ femoris bypass using reversed long saphenous vein $\frac{\bar{O}}{3}$ (Sproul, 1968; Berguer and Cotton, 1973). Arterial $\frac{}{\partial}$ flaps (Waibel, 1966), 'Dacron' (Sproul, 1968) and autogenous vein have all been used successfully for profunda angioplasty. Authors are divided in the 3 routine use of common femoral and profunda $\dot{\sigma}$ femoris endarterectomy together with a patch 3 . grafting technique whilst Cohn et al. (1971) report $\delta$ excellent results using endarterectomy alone without $₹$ patch grafting.

Important aspects of the radiology of the common femoral artery bifurcation were highlighted by Beales et al. (1971) who emphasized that the posterolateral inclination of the profunda femoris artery at or its origin made accurate estimation of stenosis in $N$ this vessel impossible in standard A-P arteriograms. Significant profunda origin stenosis was found in 0 $39 \%$ of patients in his study; in nearly $2 / 3$ of these, this was only apparent on oblique or lateral $\frac{\mathbb{D}}{\mathbb{D}}$ radiographs.

The haemodynamic theory of operations on the $T$ 
profunda femoris origin has been well described in a recent paper by Berguer et al. (1975) These authors have emphasized the essential difference between the superficial femoral artery - an artery of conduction whose cross-sectional area remains essentially unchanged whilst descending into the thigh, and the profunda femoris artery - an artery of supply which rapidly branches as it descends in the thigh giving access to a large vascular bed with a rapidly increasing total cross sectional area. This difference not only appears to affect the typical distribution of atheroma within the 2 vessels, but also suggests that a suitably situated vein patch, extending sufficiently distally into the profunda, can increase the available outflow area of the common femoral artery to an extent that will overcome the area lost by superficial femoral artery occlusion. An important implication of this concept is that a functionally significant stenosis of common femoral artery outflow exists when the superficial femoral artery is occluded even without demonstrable profunda origin narrowing and that this stenosis is correctable by enlargement of the proximal profunda femoris artery.

Accurate objective assessment of the change in blood flow following profundaplasty is extremely difficult, especially since it is the exception for distal pulses to reappear even after successful surgery, in contrast to surgery on vessels which supply the limb directly rather than via a collateral network. However, direct measurement of blood flow by electro-magnetic flow meter has shown increases averaging $54 \%$ in common femoral artery flow following profundaplasty (Cotton, Roberts and Cave, 1972). Measurement of ankle systolic pressures using a Doppler ultrasound probe has proved valuable since flow can be detected in vessels with no palpable pulse. Strandness (1970) was able to show an increase in ankle systolic pressure (ASP) after proximal revascularization of the profunda femoris artery although in no case was there a return to normal values. Both Lewis and Jamieson (1972) and Martin and Jamieson (1974) have shown a correlation between improvement in ASP index (ASP/brachial systolic pressure) and symptomatic improvement after profundaplasty although both have observed lack of increase in ASP index and a lack of clinical improvement if the pre-operative ASP index exceeds 0.5. Lewis (1974) was also later able to relate quantitiative increases in ASP index with symptomatic improvement, showing that an increase of between 0.15 and 0.2 in the pre-operative ASP index was necessary for significant improvement in claudication whilst profundaplasty alone resulted in a mean improvement of only $0 \cdot 12$. Similar measurements by Hill and Jamieson (1977) have shown an increase in ASP index from a preoperative mean of 0.21 to a postoperative mean of
0.52 in a group of patients treated with profundaplasty alone or proximal profunda revascularization. More complex tests of blood flow involving preand postoperative measurement of ASP index, ASP after exercise and subsequent recovery time as reported by Fernandes et al. $(1976,1978)$ and by Thomas, Quick and Cotton (1977) have correlated well with overall clinical improvement and with increased treadmill walking distance after successful profundaplasty.

Table 1 shows the reported results of profunda femoris artery surgery without proximal reconstruction from the literature of 1969-1977. The results vary widely with success rates of between 28 and $100 \%$ when profundaplasty is used for either claudication or rest pain and gangrene. This wide variation can be partially accounted for by differences in patient selection, different criteria for assessing success and different length of follow-up. The results of Ward and Morris-Jones (1977) are amongst the least encouraging and this paper also contains some of the longest follow up periods (mean 4 years) and uses the most strict criteria for success. These relatively poor results, in conjunction with the fact that patients relieved of rest pain by profundaplasty are often left with residual troublesome claudication, lead the authors to the conclusion that profundaplasty should be reserved as a limb salvage procedure and then only in those cases where any form of femoro-popliteal or femoro-posterior tibial bypass is impossible.

That common femoral to calf vessel bypass is feasible as a limb salvage procedure has been demonstrated by Ferguson et al. (1978) who report a series of 172 such operations in which any patent calf vessel was used as distal run-off for the graft. Their reported patency rate is $39 \%$ amongst survivors at 3 years, but the in-hospital mortality of $7.8 \%$ is much higher than would be expected in a comparable series of profundaplasties and, moreover, when a 3-year mortality of $40 \%$ is taken into account the overall success rate at 3 years is $26 \%$.

A recent paper by Myers et al. (1978) has assessed many of the factors influencing the rate of limb salvage in a large series of severely ischaemic limbs. Profunda revascularization by proximal endarterectomy or profundaplasty showed an encouraging salvage rate, by the life-table method, of $70 \%$ amongst survivors at 5 years. The influence of sympathectomy in the series is difficult to assess since many patients had both arterial reconstruction and sympathectomy at various stages but results are certainly good enough for the authors to prefer sympathectomy to femoro-tibial bypass as a primary treatment and to suggest the initial use of sympathectomy in patients with grossly infected gangrene.

Reports of the results obtained by the use of 
TABLE 1. Reported results of profunda surgery 1969-1977

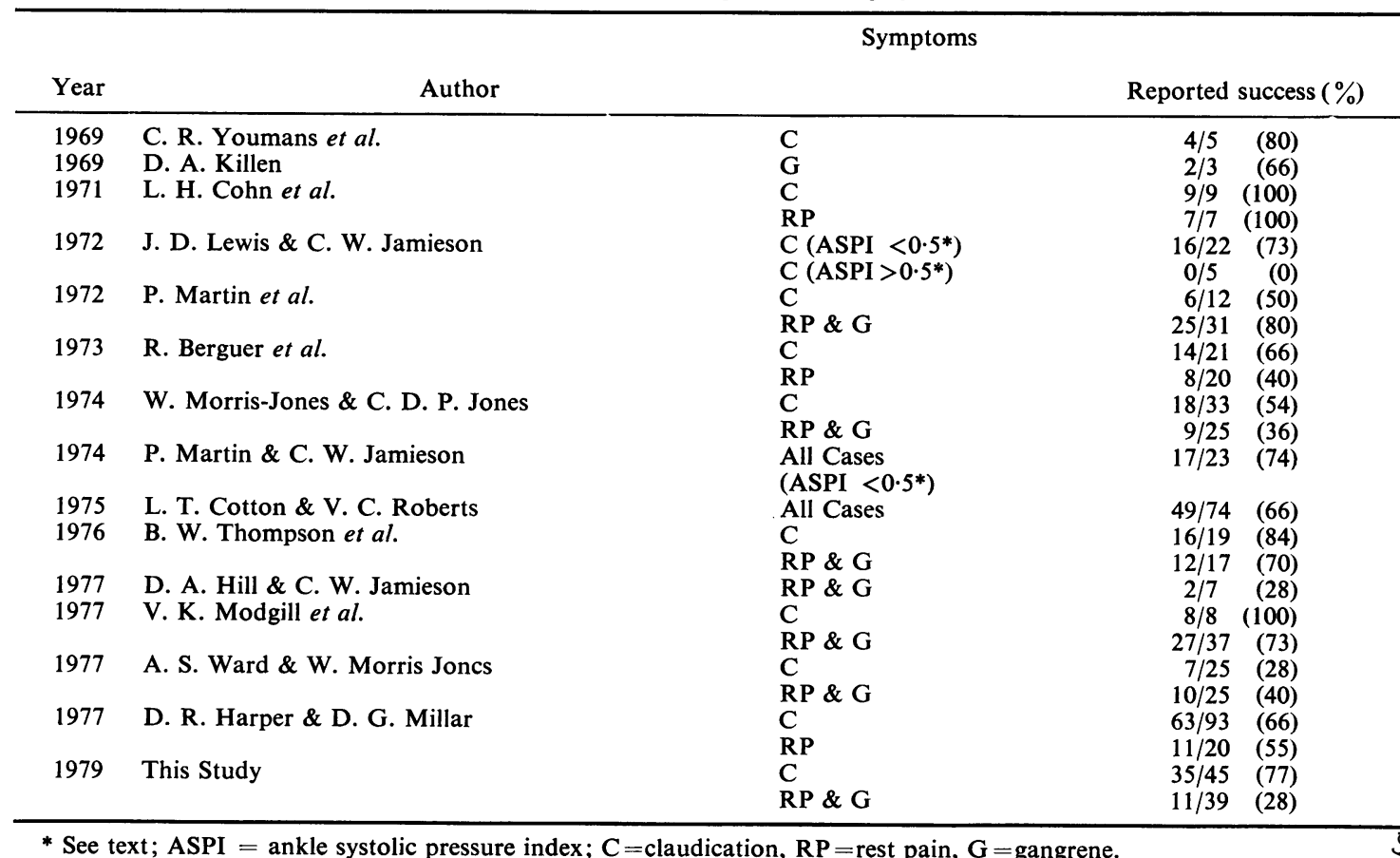

* See text; ASPI = ankle systolic pressure index; $C=$ claudication, $R P=$ rest pain, $G=$ gangrene.

profundaplasty in isolation have been published for almost 10 years but the exact position of the operation in this situation is still far less accurately defined than is its use as an adjunct to proximal revascularization procedures. It was therefore decided to review the results obtained over a 3-year period in a District General Hospital where, to a large extent, profundaplasty alone had been used to treat patients with a wide range of symptoms resulting from superficial femoral artery occlusion whether or not such patients were technically suitable for other procedures.

\section{Patients and methods}

This investigation concerns patients with lower limb ischaemia treated by profundaplasty at Southend and Rochford Hospitals during the period January 1975 to March 1978. Ninety such patients underwent operations, 9 of them bilaterally, giving a total of 99 limbs studied. The study is restricted to those patients in whom profundaplasty was the sole operative procedure, thus excluding patients in whom profundaplasty was combined with proximal disobliteration or bypass grafts.

Particularly in the latter half of the study period, profundaplasty has been the operation of choice for patients with femoro-popliteal artery diseasêt. femoro-popliteal bypass has been used on a very few occasions.

All but one patient have been under the care of a single consultant surgeon and operations have been performed by him (56) or by one of a small number of registrars (43). No fixed operative technique has been employed but in all cases an attempt has been made to enlarge the origin of the profunda femoris artery by arteriotomy and patch grafting extending at least beyond one major branch of the profunda 3 femoris artery and terminating in a relatively disease-free portion of the artery. The majority of 3 . such grafts have thus been between 4 and $6 \mathrm{~cm}$ in $\delta$ length, although grafts as long as $15 \mathrm{~cm}$ have been $₹$ used occasionally. The patients own long saphenous $ᄋ$ vein was used whenever possible as patch material, woven 'Dacron' being employed when suitable vein was not available. Endarterectomy of the common femoral artery and proximal profunda femoris or artery was not employed routinely but large and $N$ localized plaques of atheroma were removed at the N discretion of the surgeon.

Postoperative out-patient assessment with followup periods of 6 to 30 months (mean 19 months) has been by one of the group of surgeons involved. @ Patients have been allocated to one of 3 groups on 7 
the basis of their pre-operative symptoms. Group 1 contains patients with intermittent claudication limiting walking to between 20 and 200 yards. Group 2 is a small group of patients all of whom suffered varying degrees of nocturnal rest pain in the affected foot together with numbness and coldness. None of the patients in this group was able to walk more than 50 yards because of claudication. Group 3 consists of those limbs with continuous severe rest pain and either established or threatened gangrene.

In the immediate postoperative period and at each subsequent out-patient visit each limb has been classified as either a success or a failure. Thus, depending on pre-operative symptoms, a successful limb would be one in which claudication distance was significantly improved, rest pain alleviated or previously inevitable major amputation avoided. Several limbs in the successful group required amputations of already gangrenous toes. Limbs which demonstrated no improvement, deteriorated or required major amputation during the follow-up period have been classified as failures. Such a system of postoperative classification is obviously dependent upon both the surgeon's own clinical assessment of the limb and upon the patient's opinion of his symptoms, particularly as regards claudication distance.

The mean age of the patients studied was 67.5 years (range 50-87 years). There were 75 males (mean age 67 years; range 50-87 years) and 15 females (mean age 70 years; range 58-83 years) 10 patients were diabetic.

\section{Results}

Overall results in the 3 groups at the latest follow-up are compared in Table 2 . Improvement rates of 77,47 and $28 \%$ are seen in Groups 1, 2 and 3 respectively.

Seven patients in Group 3 were operated on within a short period (1-3 days) of the sudden onset of limb-threatening ischaemia. Simple embolectomy of the femoro-popliteal segment was unrewarding and 5 of these patients had a successful outcome after profundaplasty.
Table 2 also compares the latest results with those at one month after surgery. Ten initially successful cases had deteriorated during the follow-up period, 5 within a short period (6-10 weeks) and 5 only after more than one year of apparent success had elapsed. There was little evidence of spontaneous improvement during follow-up in those patients whose operation was not initially successful.

Details of the amputations within the study are given in Tables 3 and 4 . Thirty-two of the original 99 limbs were eventually amputated. Forty per cent. of all amputations were finally successfully achieved at the below-knee level. Time from operation to amputation varied from 1 week to 2 years with a mean of 17 weeks.

Diabetes complicated operation in 14 limbs. Each of the groups contained diabetics and there was no significant difference in success rates between diabetic and non-diabetic patients nor was there a significant age difference between diabetic and other patients.

The life expectancy of such a group of elderly patients with peripheral vascular disease, many of whom had evidence of previous myocardial infarction, angina and hypertension is obviously poor. There were 4 deaths within a period of 3 weeks from operation, 3 in Group 3 patients and all in patients whose operation had apparently been unsuccessful.

\section{Discussion}

Patients in this study represent a largely unselected group in that profundaplasty has been the preferred operation for patients with femoro-popliteal occlusion during the period examined. All patients were similar in that they had complete occlusion of at least part of the femoro-popliteal segment and a palpable common femoral pulse with no pulses palpable distally. Atheroma of the aorto-iliac segment was demonstrable in many patients on arteriography but in none of the patients reported here was it felt clinically to be the most significant flow limiting factor.

A success rate in claudication comparable to other reported series of profundaplasties is achieved

TABLE 2. Final success rates in $\hat{\jmath}$ symptom groups

\begin{tabular}{|c|c|c|c|c|c|c|c|}
\hline & \multirow[b]{2}{*}{ Patients } & \multirow[b]{2}{*}{$\begin{array}{c}\text { Mean age } \\
\text { (years) }\end{array}$} & \multirow[b]{2}{*}{ Limbs } & \multicolumn{3}{|c|}{ Success at follow-up } & \\
\hline & & & & & $(\%)$ & $\begin{array}{r}\text { at } 6 \\
\text { Mea }\end{array}$ & $\begin{array}{l}\text { nths } \\
\text { onths) } \\
(\%)\end{array}$ \\
\hline $\begin{array}{l}\text { Group } 1 \\
\text { Group } 2 \\
\text { Group } 3\end{array}$ & $\begin{array}{l}41(34 \mathrm{M}) \\
14(11 \mathrm{M}) \\
35(30 \mathrm{M})\end{array}$ & $\begin{array}{l}63 \\
70 \\
72\end{array}$ & $\begin{array}{l}45 \\
15 \\
39\end{array}$ & $\begin{array}{r}38 \\
9 \\
16\end{array}$ & $\begin{array}{l}(84) \\
(60) \\
(41)\end{array}$ & $\begin{array}{r}35 \\
7 \\
11\end{array}$ & $\begin{array}{l}(77) \\
(47) \\
(28)\end{array}$ \\
\hline
\end{tabular}

$\mathbf{M}=$ male. 
together with a worthwhile salvage of gangrenous or pre-gangrenous limbs. Operative mortality is low for the type of patient involved and other postoperative complications are very uncommon.

It has been noted that results of successful profundaplasty are somewhat less spectacular than those of successful femoro-popliteal bypass both in cases of claudication and rest pain/gangrene but this may be considered a reasonable price to pay for the advantage of a quicker operation with lower morbidity and mortality. Moreover, it has been shown that the subsequent amputation rate following initially successful profundaplasty is lower than the corresponding rate for initially successful femoropopliteal bypass (Martin and Bouhoutsos, 1977).

TABLE 3. Amputation within study group

\begin{tabular}{cccc}
\hline Group & $n$. & $\begin{array}{r}\text { No. of } \\
\text { failures }\end{array}$ & $\begin{array}{c}\text { No. of } \\
\text { amputations }(\%)\end{array}$ \\
\hline 1 & 45 & 10 & $2(4 \cdot 5)$ \\
2 & 15 & 8 & $5(33)$ \\
3 & 39 & 28 & $25(64)$ \\
Total $^{*}$ & 99 & 46 & $32(32)$ \\
\hline
\end{tabular}

The results from this review of the largely nonselective use of profundaplasty in femoro-popliteal occlusion do not indicate that this operation represents the sole solution to the problem. However, it is significant that an appreciable proportion of patients in all groups have been improved by the procedure and it has obviously been in these patients' interests to have been treated by the simplest procedure available.

TABLE 4. Sites of amputation required

\begin{tabular}{lcc}
\hline & $\begin{array}{c}\text { Initial } \\
\text { amputation level }\end{array}$ & $\begin{array}{c}\text { Eventual } \\
\text { healed level }\end{array}$ \\
\hline Below knee & 22 & 13 \\
Above knee & 9 & 18 \\
Through knee & 1 & 1 \\
\hline
\end{tabular}

Success in these patients must, nevertheless, be balanced against the fact that patients in whom profundaplasty was not successful when performed as a limb salvage procedure almost inevitably came to amputation. A certain number of these limbs were almost certainly not salvageable by any procedure but it might be argued that in others profundaplasty alone was insufficient, perhaps because the stenosis at the profunda origin was not the most critical flow-limiting factor in the limb.

Further advance in the treatment of lower limb ischaemia will, it seems, depend on the ability to define accurately the relative functional importance made by disease at each site in the arterial tree as is promised by current developments in the field of
Doppler ultrasound technology (Gosling and King, 1974). It may then, it is hoped, be possible to isolate with some precision a group of patients fortunate enough to be treatable by the simple procedure of profundaplasty with a very high expectation of success.

\section{References}

Beales, J.S.M., Adcock, F.A., Frawley, J.S., Nathan, B.E., McLachan, M.S.F., Martin, P. \& Steiner, R.E. (1971) The radiological assessment of disease of the profunda femoris artery. British Journal of Radiology, 44, 854.

Berguer, R. \& Cotton, L.T. (1973) Reversed autogenous saphenous vein bypass from the common to the deep femoral (profunda femoris) artery. British Journal of Surgery, 60, 676.

Berguer, R., Cotton, L.T. \& Sabri, S. (1973) Extended deep femoral angioplasty. British Medical Journal, 1, 469.

Berguer, R., Higgins, R.F. \& Cotton, L.T. (1975) Geometry, blood flow and reconstruction of the deep femoral artery. American Journal of Surgery, 130, 68.

Cohn, L.H., Trueblood, W. \& Crowley, L.G. (1971) Profunda femoris reconstruction in the treatment of femoro-popliteal occlusive disease. Archives of Surgery, 103,475 .

Cotton, L.T., Roberts, V.C. \& Cave, F.D. (1972) The value of the electromagnetic flow meter in arterial reconstructions. In: Blood Flow Measurement (Ed. by Roberts, C.) p. 107. Sector Publishing, London.

Cotton, L.T. \& Roberts, V.C. (1975) Extended deep femoral angioplasty: an alternative to femoro-popliteal $\delta$ bypass. British Journal of Surgery, 62, 340.

FARLEY, H.H., KISER, J.C. \& HITCHCOCK, C.R. (1964) Profunda femoris-popliteal shunt. Annals of Surgery, $160,23$.

Ferguson, I.A., Rosengarten, D.S., Stuchbery, F.E. \& BARNeTt, A.J. (1978) Arterial reconstruction extending below the popliteal bifurcation. British Journal of Surgery, $65,410$.

Fernandes e Fernandes, J., Nicolaides, A.N., Angelides, N.A. \& Gordon Smith, I.C. (1978) An objective assessment of common femoral endarterectomy and profundaplasty in patients with superficial femoral occlusion. Surgery, 83, 313.

Fernandes e Fernandes, J., Nicolaides, A. N., Angelides, N.A., GoRdon Smith, I.C. \& LeWIS, J.D. (1976) An objective assessment of profundaplasty. British Journal of Surgery, 63, 661.

GosLING, R.G. \& KING, D.H. (1974) Arterial assessment by Doppler-shift ultrasound. Proceedings of the Royal Society of Medicine, 67, 447.

HARPER, D.R. \& MillaR, D.G. (1977) Simple conservative profundaplasty in lower limb ischaemia. Journal of the Royal College of Surgeons of Edinburgh, 88, 197.

Hill, D.A. \& JAmieson, C.W. (1977) The results of arterial reconstruction utilising the profunda femoris artery in the treatment of rest pain and pre-gangrene. British Journal of Surgery, 64, 359.

Kiely, P.E., Lumley, J.S.P. \& TAYloR, G.W. (1973) Extended endarterectomy of the profunda femoris artery. Archives of Surgery, 106, 605.

KiLLEN, D.A. (1969) Salvage of the leg by revascularization of an occluded deep femoral artery. Surgery, 66, 506.

LeEDS, F.H. \& GilfillaN, R.S. (1961) Revascularization of the ischaemic limb (importance of the profunda femoris artery). Archives of Surgery, 82, 25. 
LEwIS, J.D. (1974) The role of measurement in peripheral vascular surgery. Proceedings of the Royal Society of Medicine, 67, 443.

Lewis, J.D. \& Jamieson, C.W. (1972) Pressure and flow in blood vessels. Proceedings of the Royal Society of Medicine, 65, 1121.

Martin, P. \& Bouhoutsos, J. (1977) The medium term results after profundaplasty. British Journal of Surgery. 64, 194.

Martin, P., Frawley, J.E., Barabas, A.P. \& Rosengarten, D.S. (1972) On the surgery of atherosclerosis of the profunda femoris artery. Surgery, 71, 182.

Martin, P. \& JAmieson, C.W. (1974) The rationale for and measurement after profundaplasty. Surgical Clinics of North America, 54, 95.

Martin, P., Renwick, S. \& Stephenson, C. (1968) On the surgery of the profunda femoris artery. British Journal of Surgery, 55, 539.

Modgill, V.K., Humphrey, C.S., Shoesmith, J.H. \& KeSTer, R.C. (1977) The value of profundaplasty in the management of severe femoro-popliteal occlusion. British Journal of Surgery, 64, 362.

Morris, G.C., Edwards, W., Cooley, D.A., Crawford, E.S. \& DeBAKeY, M.E. (1961) Surgical importance of the profunda femoris artery. Archives of Surgery, 82, 32.

Morris-Jones, W. \& JoNES, C.D.P. (1974) Profundaplasty in the treatment of femoro-popliteal occlusion. American Journal of Surgery, 127, 680.

MYeRS, K.A., KING, R.B., Scotr, D.F., Johnson, N. \& MoRRIS, P.J. (1978) Surgical treatment of the severely ischaemic leg: 2. Salvage rates. British Journal of Surgery, $65,779$.

SPROUL, G. (1968) Reconstruction of the profunda femoris artery. Surgery, 63, 871.

STRANDNESS, D.E. (1970) Functional results after revascularization of the profunda femoris artery. American Journal of Surgery, 119, 240.

Thomas, M.H., Quick, C.R.G. \& Cotron, L.T. (1977) Doppler ultrasound in the functional assessment of extended deep femoral angioplasty. British Journal of Surgery, 64, 368.

Thompson, B.W., Read, R.C., Campbell, G.S., Slayden, J.E. \& BOYD, C.M. (1976) The role of profundaplasty in revascularization of the lower extremity. American Journal of Surgery, 132, 710.

Waibel, P.P. (1966) Autogenous reconstruction ofthe deep femoral artery. Journal of Cardiovascular Surgery, 7, 179.

WARD, A.S. \& Morris-Jones, W. (1977) The long term results of profundaplasty in femoro-popliteal occlusion. British Journal of Surgery, 64, 365.

Youmans, C.R., Hopkins, J.W. \& DeRriCK, J.R. (1969) Transinguinal distal profunda femoris revascularization. American Journal of Surgery, 118, 909. 